\title{
The Politics of Collective Repair.
}

Examining Object-Relations in a Postwork Society

\section{Dr Valeria Graziano}

Post Doctoral Research Fellow,

Art and Design Research Institute,

Middlesex University London,

Hendon campus

The Burroughs

London

NW4 4BT

07986262273

V.Graziano@mdx.ac.uk

\section{Dr Kim Trogal}

Lecturer Architecture \& Design History \& Theory

Canterbury School of Architecture

University for the Creative Arts

New Dover Road

Canterbury,

Kent

CT1 3AN

07967683385

KTrogal@ucreative.ac.uk

\section{Abstract}

In this article we look at repair as an emergent focus of recent activism in affluent societies, where a number of groups are reclaiming practices of repair as a form of political and ecological 
action. Ranging from those that fight for legislative change to those groups who are trying to support ecological and social change through everyday life practices, repair is beginning to surface tensions in everyday life and as such poses opportunities for its transformation. We survey a few of the practices that make up this movement in its various articulations, to take stock of their current political import.

While we suggest that these practices can be seen as an emergent lifestyle movement, they should not be seen as presenting a unified statement. Rather, we aim to show that they articulate a spectrum of political positions, particularly in relation to the three specific issues of property, pedagogy and sociality. These three dimensions are all facets of current internal discrepancies of repair practices and moreover express potential bifurcations as this movement evolves. Drawing on a diverse methodology that includes discourse analysis and participant observation, we suggest some of the ways in which this growing area of activity could play a significant role in resisting the commodification of the everyday and inventing postwork alternatives.

Keywords: repair, postwork, commons, property, feminist pedagogy, object-relations

\section{Word count: 9537}

\section{Introduction}

The problems associated with the contemporary 'throwaway' culture are widely known, for instance in relation to the ecological implications of the high levels of the embodied energy of products, their volume and their increasingly short life spans are connected to the emissions of GHGs in distribution and disposal processes, the diminishing of natural resources, alongside other social problems, such as the intensification of work exploitation and increased rhythms it demands in order to participate (Crary, 2013). While reactions to the problem have led to diverse range of actions, such as 'alternative consumer practices' (Littler, 2009), in this paper we focus on the recent phenomenon of 
the collective repair practices of goods that are emerging as a transnational form of resistance to the dominant 'throwaway' paradigm.

In this paper, we focus specifically on collective practices working with the repair of electronics, household consumer goods and of clothing, as these are amongst the everyday objects where planned obsolescence is at its most visible. For example, mobile phones are used on average for 18 months, or the prevalence of 'fast fashion' with an estimated 350,000 tonnes (around $£ 140$ million worth) of used clothing going to landfill in the UK every year (WRAP, 2016). In response, repair is fast becoming the hinge around which an array of diverse social initiatives and civil society organisations are emerging.

In recent years, the subject of repair has already been provoking new debates across a variety of disciplines. As Steven Jackson has remarked, repair has the capacity to connect across diverse fields and interests $(2014$, p. 222), whose emerging discourse crosses design, new media, urban geography, law and science and technology studies, amongst others. Across all these different specific disciplines however, studies of repair practices and cultures are fostering important discussions that are political in nature, going beyond the confines of specific disciplines.

In the field of design practitioners have been working against planned obsolescence and the integrated technologies and components of consumer products, which both affect our ability to repair and sustain the life of objects (cf. Cooper et al. 2015, Fulton Suri 2009, r-riparabile.com 2015). However, recent studies such as Ames and Rosner (2014) highlight the gap between designers' ideas about how products will be used and treated, and the processes that actually take place on the ground, by which a variety of different actors are involved in sustaining the life and use of an item. The contingent material practices of repair, and the constellation of different people called upon when an item fails, can reinforce existing social hierarchies and exclusions through the access (or lack of) to material items, parts and most importantly knowledge and confidence.

Following new media scholar Peter Jackson's idea of 'broken world thinking', focussing on repair brings specific perspectives and insights to the material world. While Jackson suggests that "breakdown, dissolution and change, rather than innovation, development or design" are the central themes and problems facing new media and technology, the epistemological (and pedagogical?) implications of this premise extends wider. In urban geography, Stephen Graham and Nigel Thrift 
(2007) similarly emphasised that the breakdown of urban infrastructures, as both the moment when the systems supporting our existence become exposed, and that this exposure offers the opportunity to revisit them. While it has been argued that breakdown and repair are the means by which societies learn (Brand, 1994), and that repair and maintenance has long been understood as taking a role in the production of scientific knowledge and the development of technologies in STS (Denis et al. 2015), it is precisely because of its implication with material process and forms of power-knowledge (Foucault 1980), that collective repair practices should be seen as a site of resignification of the everyday.

While we agree that "broken world thinking" will play a crucial role in the transformation of economic and social systems in the coming future, we are careful that this trope cannot be taken at face value as a guarantee of progressive practices per se. As the repair movement grows in numbers and importance, further reflections on its positioning in relation to the broader societal and political issues in which it is inevitably implicated are needed. The diverse initiatives of collective repair represent sites where key discussions around current cultural and political issues can be confronted in an embedded manner.

Building upon this transdisciplinary body of work, this article highlights the political implications of different ways of organizing around collective repair. As the repair movement grows in numbers and importance, further reflections on its positioning in relation to the broader societal and political issues in which it is inevitably implicated are needed, short of it becoming a hollow keyword.

\section{Introducing a movement}

In the last ten to fifteen years, a number of new and important forms of organizing around repair for ecological transition have emerged across the 'global North'. These span from campaigns to change legislation, repair cafes, community tool libraries and online fora, which are coalescing around a growing desire to revisit, through fixing, our relationship with the objects and machines that make up our daily lived environments and sustain our mundane activities within it. In the present moment repair is thus emerging as an extra-disciplinary preoccupation around which a number of heterogeneous subjects are becoming politicized. Such processes of politicization, meaning a 
becoming more aware of the dynamics of power shaping interconnected and common issues, is observable in a range of diverse initiatives (some of which are discussed in this paper) that use repair both as a concept and as a site of collective intervention and sharing of knowledges, to the point where they can be, as we propose later on, be considered together to constitute an emerging social movement.

While different approaches to the definition of a social movement exist within social theory, many converge around key characteristics. Following a well recognized formulation by Mario Diani (1992), a minimal working definition of a social movement can be formulated as "a process whereby several different actors, be they individuals, informal groups or organisations, come to elaborate, through their joint action and/or communication, a shared definition of themselves as being part of the same side in a social conflict. By doing so, they provide meaning to otherwise unconnected protest events or symbolic antagonistic practices, and make explicit the emergence of specific conflicts and issues" (p. 2-3).

While in a commonly held view is that social movements are considered distinct from lifestyles, we would like to draw on Ross Haenfler, Brett Johnson and Ellis Jones's conceptualization of 'lifestyle movement' (2012) to frame the emergent politics of collective repair. The notion of 'lifestyle movement', describing sites of political action at "the intersection of lifestyle and social movements" (Haenfler, Johnson and Jones 2012), has the merit of simultaneously broadening the conceptualization of social movement's action 'beyond contentious politics' (Snow 2004, p. 19) and at the same time it can allow for the conscious development of a way of life and personal everyday activities to be considered as valid tactics to foster broader socio-political change.

In the light of contemporary developments in social movement studies, such concept revisit a characteristic that accompanied the developments of social justice movements since the 1970s, which commentators at the time framed as a 'prefigurative politics' (Gorz, 1968; Boggs, 1977). These differed from earlier forms of political organizing (such as those of the international workers movement), as they pursued "the embodiment within the ongoing political practice of the movement, of those forms of social relations, decision making, culture, and human experience that are the ultimate goal” (Boggs 1977, p. 100). 
The hypothesis put forward here is that contemporary collective repair practices should be seen as a 'lifestyle movement' rather than simply as a lifestyle choice, as their investments in an ethos of sharing, commoning and mutuality reveals a effort to participate in the construction of political alternatives. This sets them apart from, for instance the 1950s-DIY phenomenon. At that time, the DIY movement drew attention to problematics such as the experience of alienation of blue collars (in the form of a new kind of nostalgia for manual labour (Gelber 1997), and the growing significance of customization and interactivity in marketing strategies. More recently however, conditions have changed in such way that have prompted some commentators to speak of a shift from DIY to DIT (from Do It Yourself to Do It Together) or DIO (Do It Ourselves) - cultures (Ratto and Boler 2014, p.38). This is a shift in the perception of use and customization from a primarily private and domestic matter and recasting it as both collective and directly political, interpelling who has the right to mould and control the material culture that shapes and supports our contemporary livelihoods in increasingly interconnected societies.

Alongside the transformation in DIY cultures, antecedents that influenced the formation of a repair movement can be traced in autonomous initiatives such as the Hackerspaces and Medialabs of the early 1990s, as well as the independent bicycle-repair workshops opened by many squatters movements across Europe since the late 1970s (Robb 2012, p. 400). While such antecedents are useful to understand the genealogy of the phenomenon, we believe that the rising movement of repairers represents a step beyond the confines of a subculture, insofar as they are drawing together heterogeneous constituencies, who have varying levels of ability and different social backgrounds.

In what follows, we explore some of the diverging political positions that are currently contributing to the shaping of such movement, to argue that rather than presenting an ideologically unified front, collective repair initiatives are sites where certain political concerns converge, yet proposed solutions and practices do not necessarily constitute a unified proposal yet.

We do this by focusing on examples that represent three different facets of this movement: the Repair Association as a case of lobbying and rights; iFixit, an example of an online community based resource for DIY; and Repair Cafes and Restart Parties, both 'public sites of repair', each represents different concerns of rights and labour, and of knowledge and skills. These cases studies were selected with the rationale of illustrating the complex composition of organizational forms and 
strategies found in the repair movement at this time. Moreover, they were selected as they expose the diversity of political positions in relation to the key issues of property, pedagogy and work, allowing us to examine some of the most significant political tensions, and potential bifurcations, currently at stake in repair.

Significantly, all the selected examples have been established post-2000 and are predominantly based in the 'Global North'. The rapidity of these initiatives' success and spread reflects (relatively) affluent citizens' increasingly widespread concern over the levels of consumption, the generation of waste and its devastating impact.

We approach repair as critical theorists and practitioners with a background in urban studies and critical organization theory. We use a combination of methodologies, including: Foucauldian critical discourse analysis (Jager and Maier, 2009), preoccupied with the emergence of valid knowledges and how they are passed on among subjects participating in a certain practice; of onlineethnography (Murthy, 2011), taking into account the textual production created by the computermediated interactions of participants in collective repair communities online; and auto-ethnographic elements, generated as we became actively involved within specific repair initiatives.

\section{Repairs, Enclosures and Markets}

Broken world thinking asserts that breakdown, dissolution, and change, rather than innovation, development, or design as conventionally practiced and thought about are the key themes and problems facing new media and technology scholarship today. (Jackson 2014, p. 222)

The technologies that have recently been reshaping our households have been enclosing aspects of our everyday lives, restricting freedoms around our ability to re-use, resell and, significantly here, our ability to repair the things we thought we 'owned' (Repair.org nd.). For example, household gas boilers, the dominant way UK households get hot water and heat their homes are becoming 'smart' 
pieces of equipment, which can self-diagnose where a problem lies in the event of any failure. A code is then displayed on an LED screen but only a registered engineer, who has paid membership to the company, is able to 'read' and interpret the code. Knowledge of the problem, in this instance, is enclosed property.

These moments of enclosure and the creeping power of control arising from IP, while present in the everyday, becomes most tangible at moments of failure. A high profile case such as Apple's 'Error 53' illustrates such a moment of visibility. The error affected the iPhone 6 and rendered the device useless if it had the home button replaced by an independent third party. If a non-Apple registered repairer had replaced this button, a Software update detected a 'non-standard' component and shut down the phone irrevocably. Apple's initial argument was that as the button has a touch ID fingerprint reader within it, the shutting down of the device was a security measure to protect customers from fraudulent use of the phone, particularly protecting against the misuse of Apple Pay or access to online banking. However, after being served with a class lawsuit, the company have since apologised and released a fix. As the iPhone's features (such as Apple Pay) could have been disabled without blocking the entire phone, some regarded the error as 'a cock-up rather than a conspiracy' (Restart radio 2016), whilst others saw it as a deliberate, and aggressive move against independent repairers (Brignall 2016).

Property boundaries and 'problems' like these are set to proliferate with the much vaunted 'Internet of Things', in which a projected 30 billion $^{1}$ devices and sensors will be networked, creating an 'ever-growing unprecedented flow of data' (Siemens 2014). Unsurprisingly companies such as Siemens connect this directly to GDP growth and emphasise the 'Internet of Things' 'vast economic potential [...] The IDC predicts earnings of $\$ 8.9$ trillion [...] and consulting company Deloitte and Touche estimates that the smart home market will have a volume of €4.1billion by 2017 in Europe alone.' (Ibid). The boiler's repair codes, transmissions from the 'fridge that thinks' and even our conversations mediated by telecommunications systems are all productive in the ways that they leave 'digital

\footnotetext{
1 'According to the business consultancy firm Gartner, approximately 26 billion objects will be linked together in the Internet of Things by 2020. If you add in laptops, PCs, and smartphones, which will number around seven billion by 2020 , Gartner arrives at 33 billion objects.' Published in: http://www.siemens.com/innovation/en/home/pictures-of-the-future/digitalization-and-software/internet-of-thingsfacts-and-forecasts.html [Accessed: 18 February 2016]
} 
traces wherever [they] go, traces that can be mined to generate data that enable advertising to be targeted with ever greater accuracy.' (Huws 2015) Whilst devices can, and will, communicate amongst themselves, this communication not only raises serious ethical questions around profit seeking and further enclosures in the 'endless flow of data,' but also concerns issues of control and self-determination in relation to these technologies.

In the face of these ongoing transformations, a constellation of activist networks, not for profit organizations and third sector parties have been engaging in initiatives that directly denounce these changes to the reparability of the things we buy as an alarming form of dispossession. They draw attention to ways manufacturers 'erect practical and legal barriers to repair and reuse' (Bluff 2016).

Initiatives such as the Repair Association and IFixit are documenting the increasing prevention of independent access to fixing, a process that has been described as an emergent form of intensification of the more classic 'planned obsolescence' (Packard 1960) approach to product design. Notorious cases such as 'Error 53' exemplify how dominant corporate attitudes towards independent interventions has remained consistent from the software and patents battles of the 1990s which is overspilling into the materiality of the technological objects, with significant implications both for repairers as well as our everyday relations with the world around us. As the amount of economic activity generated by repair and maintenance work increases (Graham and Thrift 2007, p.7), companies also find it increasingly profitable to extend their operations into the 'aftermarket' of their goods, primarily by monopolizing it.

Knowledge has revealed itself to be not simply a new ambit of capitalist expansion, but also a backdoor through which an intensification of the capitalist property regime across all aspects of the man-made world is enabled. This process confirms the relevance of the 'becoming rent of profit' hypothesis put forward by Carlo Vercellone in 2010. According to this view, in contemporary economies the most significant revenue is generated by the ownership of scarce (or artificially rendered so) resources of various kinds (material, such as tools or space, and immaterial, such as ideas and knowledges) and not by the classical form of profit generated by industrial production. On the one hand, there is a line of corporate reasoning, driving for a relentless expansion property rights to all things, from genetic material, ideas to debt or mathematical algorithms. Whilst this disquieting expansion is fast moving from the somewhat hard-to-perceive realm of ideas back into 
the materiality of our object-world, it has as its object of governance the uses, knowledges and behaviours associated with objects themselves, in short, the totality of the forms of life in their most intimate and minute dwellings. This represents a dynamic of dispossession that is unprecedented in its capacity to decouple ownership from both use and knowledge of everyday objects in a new radical way and thus directly interferes with the repair and maintenance of these things.

One of the major actors bringing this to attention is the US-based The Repair Association, formed in 2013 and built on a previously existing network named the Digital Right to Repair Coalition. The Repair Association now has 48 organizational members, working at both national level, and at state level in four US states. Their efforts to resist the industry practice foregrounds the symptoms of this silent, radical re-organization of our everyday practices with objects that are dreamed up and delivered by major international corporations.

The kinds of barriers the Repair Association and others draw attention to includes manufacturers refusing to supply independent repair shops with spare parts, such as Nikon (Chamberlain 2012), developing products which are designed so they cannot be repaired, such as Keurig Coffee machines (Bluff, 2015) or changing basic components, such as Apple's introduction of 'tamper-proof' screws, ${ }^{2}$ which make third party access difficult. The Association reports that some products even come with contracts 'that interfere with your right to resell your product' (The Repair Association nd.a). Their most significant successes to date include firstly the 'right to repair' in the car industry, obliging manufacturers to use non-proprietary interfaces to diagnose problems and provide access to repair information and parts (Nelson 2014), and secondly making phone unlocking legal again in the US through the the 'Unlocking Consumer Choice and Wireless Competition Act' (2014). They are now targeting electronics and consumer appliances whose manufacturers have erected similar repair monopolies, often where components are locked down via passwords that are only accessible to those with a license.

As well as providing a network and forum to connect repair workers, their primary activity is lobbying and advocating for legislative change. The Repair Association aims to protect 'rights to

\footnotetext{
2 The specific example is Apple's use of a new screw head that is shaped like a flower: 'This screw head is new to us. In fact, there isn't a single reputable supplier that sells exactly the same screwdrivers Apple's technicians use-which is Apple's point. They picked an obscure head that no one would have. This new screw defeats even our vaunted 54-bit driver kit, which until now we've been able to claim that it's all you need to disassemble just about any consumer electronics.' (Weins, 2011)
} 
repair' for 'hobbyists and independent repair technicians, to environmental organizations and the aftermarket' (The Repair Association nd.a). In their lobbying, they explain 'Fair Repair would require manufacturers to provide owners and independent repair businesses with fair access to service information, security updates and replacement parts' (ibid).

The Repair Association represents (in the main) the repair industry and small businesses, yet the right to repair is also being defended as a cultural problem, particularly for DIY-ers whose activities are as restricted as those working independently. iFixit, one of the founding members of the Repair Association, also advocates for rights for local repairers and DIY-ers. Founded in 2003 by Luke Soules and Kyle Wiens, iFixit is 'a wiki-based site that teaches people how to fix almost anything. Anyone can create a repair manual for a device, and anyone can also edit the existing set of manuals to improve them' (iFixit nd.a). iFixit fund themselves through the selling of tools and parts for repair, a model that allows them to support a range of other activist practices (iFixit nd.b). They are aiming to make available a free repair manual for every device and at the time of writing there are 18,893 free manuals on the iFixit website, covering a range of appliances (cameras, phones, laptops) as well as household goods such as crockery, clothes and toys.

In defending and claiming 'rights to repair' The Repair Association and iFixit mobilise arguments around competitive markets, consumer choice and property for example:

A competitive repair market is vital to the economy. When manufacturers own the only repair shop around, prices go up and quality goes down. Competition is better for customers, but mom and pop repair shops are struggling with unfair practices by multinational corporations. Consumers and repair pros are starting to fight back (The Repair Association nd.b).

Repair helps create local jobs, and repair and reuse benefits the environment by reducing endof-life electronic products. The freedom to maintain, innovate, and improve upon our products is imperative. These basic freedoms are essential to American economic growth and creativity, and must be preserved for the 21 st century (The Repair Association nd.a). 
Through their argument, the Repair Association highlights the conflict between open markets for repair and increasing monopolies. Like the Repair Association, iFixit draw attention to jobs (particularly local jobs, as repair cannot easily be off-shored), they also emphasise the ecological dimensions of repair, documenting rare earth mining and the impacts of e-waste. While iFixit makes similar demands for information, parts and so on, they specifically evoke the rights of hobbyists and DIY-ers through ownership, for example:

You bought it. You own it. You have the right to improve the things you buy. If you want to paint racing stripes on your car, go for it! Ownership means you should be able to open, hack, repair, upgrade, or tie bells on it. Once you've paid money for a product, the manufacturer shouldn't be able to dictate how you use it-it's yours. If you want to make a custom wood frame for your iPod, go for it! (iFixit nd.c)

Both groups importantly evoke rights to access and sustain independent livelihoods and challenge imbalances of power that often go unacknowledged in 'the market,' classically depicted as a neutral terrain in which buyers and sellers meet as equals to exchange. While it is easy to recognise the difficulty of articulating claims in a language that law makers recognise and take seriously, as well as the need to communicate 'technical matters' with a broader audience, framing the right to repair as a matter of free access to market and consumer rights finds its limits in trying to solve a structural injustice around access and control with the very tools that have been deployed to create it.

The Repair Association and iFixit's arguments confirm Massimo de Angelis' observation that 'the extent to which we are aware of enclosures is the extent to which they confront us' (de Angelis, 2007: 144) and suggests that repair represents a crucial frontier in the political discussion that is pushing for redefinitions of the meaning of 'property'. While the campaign in favour of freedom of repair articulates their point of view as a matter of market and property, their very modes of organizing - especially if we think of iFixit's wiki, open-content structure - speaks of another possibility, that of understanding the defence of repair as a defence of a common. By this we refer to contemporary discourses on the common (Hardt and Negri 2009, Dardot and Laval 2015), which 
shifts emphasis from the commons understood as collectively managed resources (Ostrom 1990) towards the common as a regime of political practice. As Dardot and Laval summed up, while Elinor Ostrom and others focused on the institutional forms, on the rules and juridical tools used by collectivities to manage 'in common' some shared resources outside of the market:

Michael Hardt and Antonio Negri, on their part, supplied the first theory of common, which at the very least has had the historical merit of shifting the reflection from the plane of concrete experiences of commons (in the plural) to a more abstract and more politically ambitious conception of the common (in the singular). In short, 'common' has become the name of a regime of practices, of struggles, of institutions and of researches that open up towards a non-capitalist future (Dardot and Laval 2015, p. 18 - author's translation).

Whilst some might consider knowledge as a unique kind of common resource, having a special ability to resist enclosure because of its 'non-appropriable' nature, the ongoing conflict around repair practices makes tangible that knowledge commons are such not because of the nature of the resource but rather 'thanks to the dispositives that protect the production of knowledge from fences and commodification. Which means that their ratio (rationale) consists less in technical aspects than in social rules' (Dardot and Laval 2015, p. 131, author's translation).

As scholars have noted, intellectual property relies on a certain mutability that 'serves the interests of patentees' and 'plays into the perpetuation of certain inequalities particularly between holders of various property forms' (Carolan 2010, p. 123). In the context of our relations with the object world, repair foregrounds a particular ethical understanding of ownership, use and maintenance. In their repair manifesto iFixit write 'if you can't fix it you don't own it,' (iFixit nd.d) which on the one hand declares a right to fix connected to ownership, but on the other could also be taken to mean that ownership is reframed in terms of responsibility, stewardship, and repair. As recently put by the 'custodians', a network of free knowledge activists, we should be 'useful to the things we own.'3

\footnotetext{
3 'In Antoine de Saint Exupéry's tale the Little Prince meets a businessman who accumulates stars with the sole purpose of being able to buy more stars. The Little Prince is perplexed. He owns only a flower, which he waters every day. Three volcanoes, which he cleans every week. "It is of some use to my volcanoes, and it is of some
} 
While this idea was put forward in defence of open access online libraries against the paywalls put up by major academic publishers, we believe that this principle carries some traction in relation to repair.

Thus, if repair is to be claimed back as a right, it needs to be claimed as a right to a common or not be at all. To defend in the name of open markets and fuller property rights means to miss the macroscopic point that under the current neoliberal regime the law is not only used to create markets to replace any other kind of social practice, but crucially does so in favour of the more powerful.

\section{Repair Pedagogies}

As with the discourse around rights, collective sites of repair also offer a spectrum of different pedagogical approaches. The pedagogical aspects of repair movements are a useful site to study not only in relation to the commoning of knowledges, but also because they are testing assumptions around the connection between learning skills and long term change.

On top of educational activities online, expressed by the phenomenon of online tutorials and sharing of information such as the ones hosted by iFixit, over the last decade a number of local initiatives have been taking a hands-on approach to the pedagogy of repair. One of the most well established of these are the Repair Cafés, inaugurated in 2009 by Martine Postma in the Netherlands, who went on to start the Repair Café Foundation, a non-profit organisation in 2011. In this short time, 986 Repair cafes have been set up across 24 countries. They are, as Daniela Rosner and Morgan Ames called them, 'public sites of repair,' contributing to the shift from repair seen as a 'family responsibility to societal imperative.' (2014, p.55)

The format of repair cafes is quite straightforward, they are 'pop-up' events, often held on a regular basis, which people can attend free of charge and bring their broken items. After explaining the problem to volunteers, they are directed to the appropriate repair station where a volunteer expert will (hopefully) be able to diagnose the problem, give advice on how to repair the item and, where it is feasible, actually carry out the repair. This format has also proven popular with other non-profits and community groups internationally, as well as the one local to us, The Restart Project. This is a 
London based registered charity and social enterprise that also aims to encourage people to use their electronics longer, with an emphasis on sharing repair and maintenance skills. Similar to the Repair Cafe's format, Restart organise 'Restart Parties,' free to attend events where anyone can bring along their broken goods and volunteer experts (called 'restarters') offer help in fixing them. Like the Repair Cafes, Restart is fast growing and at the time of writing there have been around 200 Restart parties in eight different countries. Their aim is to create a movement; any group can throw a Restart Party anywhere, with the original organization providing guidance on how to do so.

For both Repair Cafes and Restart Parties, the pedagogical aspect is an important tool for socioecological change. For example, The Repair Café write:

People who might otherwise be sidelined are getting involved again. Valuable practical knowledge is getting passed on. Things are being used for longer and don't have to be thrown away. [...] The Repair Café teaches people to see their possessions in a new light. And, once again, to appreciate their value. The Repair Café helps change people's mindset. This is essential to kindle people's enthusiasm for a sustainable society" (Repair Cafe nd).

Similarly, Restart commented about their parties:

The focus of the events is on skill-sharing and learning. Participants take active part in the repair and help in troubleshooting, supported by an experienced volunteer. Members of the public can bring a broken item or just learn by watching the talented repairers at work. It is also easy for new people to volunteer their skills (Restart Project 'Information about the Restart Parties' nd).

The popularity and rapid spread of Repair Cafes and Restart Parties reveals a great demand for public sites of learning that are free and accessible. One key aspect of these initiatives is their local character, which helps to ensure the participation of a transversal constituency, which includes more motivated amateur diy-ers alongside those who more simply wish to take advantage of local cultural offers. 
As attendees at Restart Parties, our initial experiences revealed that while the accessible format of encounter privileged within repair movements is proving effective as a context for demonstrating the potentiality of repair as a social practice, they might be less so in the face of the more pedagogical objectives that these initiatives aim for in the long run. In our own case, based on the attendance of three events in London as repair beginners, our capacity to learn by observation was limited by starting with a low-level of knowledge when faced with the complexity of the problem at hand (in our case, a broken lamp). If one does not know the difference between Amps and Volts, or how transformers work, it can be difficult to follow any teacher who does not have time to start 'from the beginning'. The question of how to sustain a transition from beginner to more proficient is difficult, and what is possible in a meeting perhaps lasting 10-20 minutes, raises a question about how such learning could be sustained on the ground. The learning that takes place is greater for the volunteer experts, who do learn by doing, confronting new problems each session, informally swapping skills amongst themselves and asking for help when trying to fix devices (Restart Project 2015a). The differences, between ambition and practice, are confirmed by Rosner and Ames in their extensive ethnographic study of the Fixit Clinic in Albany, California (Rosner and Ames 2014). This initiative was created with much of the same approach that animates the Restart Parties and other selforganized groups gathering around collective repair. Rosner and Ames' analysis draws out complications and ethical difficulties in these new social sites of repair. Some of the contradictions they noticed include: the reiteration of gender divides, with women 'naturally' being more tentative or passive in their approach to repair than men; the continued reliance on volunteer experts for diagnosis and more complex fixing, a tendency that reinforces the authority of the expert rather than challenging it; a lack of shared reflexivity around which objects are deemed worthy or repair and which ones are turned down (too complex, expensive or long to fix) or simply never brought to the initiative in the first place (Ibid.). The transformative opportunity collective repair practices generate are at risk of reproducing existing hierarchies. As Rosler and Ames show the emergence of expertise follows patterns consistent with dominant social divisions and consequently builds barriers to independent repair (Ibid.).

The Restart Project similarly observed a gender divide at their parties, where $90 \%$ of the volunteers are male. 'Spontaneous' actions in current pedagogical formats do not challenge gender stereotypes and, as Restart say, the strategic use of stereotypes to increase involvement 'risks taking 
you backwards' (Restart Project 2015a). In response, Restart have been holding a series of women only skill-share workshops called Rosie Restarter (also open to people with non-binary gender identities). This aims not simply to diversify the cohort of volunteers as a representational problem, but aims to address problems in an affirmative way creating new contexts for experience. Restart's founders speak here of the importance of role models, which is not about 'scientists in high heels' or 'pink tool sets' but rather a diversity of possibilities of subject positions, in which participants can be exposed to many different women doing different kinds of technical activities (Restart Project 2015a). The willingness of organizations such as Restart to openly discuss the pedagogical difficulty of challenging gender normativity is a significant gesture towards incorporating reflective practices in this kind of grassroots organizing. This could be an important component of the politics put forward by repair movements, not only to do with gendered issues, but also expanding into other kinds of structural inequalities such as education, class, and race.

The challenges raised by these pedagogical practices has parallels with feminist critiques of classroom education. In this context, commentators have been exposing how mainstream assumptions around how people learn new skills and modify their cognitive habits, neglect key aspects of the relational dimension of learning. This is particularly significant amidst the intensification of microprocessors into everyday objects, which means that some knowledges come to feel further away and less possible to 'obtain', given the levels of expertise required.

In particular feminist critiques highlight the need to recognise the student as a whole person, not only the moment they are in the class (hooks 1994) and to recognise that beyond the actual technique what matters is the intentionality of the instructor, as well as the other participants. Moreover, feminist critique highlights the need to supplement event-based and long-distance learning - prevalent in the cultural sector at large at the moment (with short, intensive 'workshops' being the cornerstone of much public programming and increasingly educational provisions) with approaches that allow for longer-term pedagogical situations to evolve.

Commentators such as Elisabeth Ellsworth, Erica Meiners, and Therese Quinn argued that in the experience of many teachers, what ultimately changes people's quotidian practices, orientations and beliefs is to just commit and show up every day, to show up when you are tired and to endure the students when they are in a bad mood, or to put up with them when they speak back at you (Ellsworth 1989, Meiners and Quinn 2007). This has little to do with the canonical paradigms of critical pedagogy 
understood as a grand performative gesture, and more to do with the fact of being a presence in someone else's life who is caring, who 'shows up' and does not give up on the process of change, which takes time and is not linear. This is the enduring aspect of teaching, which needs to allows for different cycles and speeds to exist. The teacher here is portrayed as someone who builds confidence in someone by 'sticking with them,' that is persevering in both the relationship and the process of change. While this critique has been developed in the context of classroom teaching, we believe these arguments contain important points for the future development of a repair movement, as another instance encountered in our ongoing research exemplifies.

ànticasartoriaerrante is a project based in Turin, Italy, focusing on teaching sewing, up-cycling and mending techniques, and elaborating alternative communicative approaches to the problem of sustainable fashion. Learning and teaching how to repair clothes is one of their many activities, and one that plays a significant role in the extensive community of practice, supporting over 400 learners in the course of 5 years of activity. While this project is focused on garment construction, its broader aims are comparable with the repair initiatives outlined earlier, as it addresses the issues of labour exploitation, deskilling as well as the environmental impacts of fashion. Sara Conforti, founder of the project, reflected on the importance that a 'pedagogy of perseverance' plays in the context of ànticasartoriaerrante:

It is when the stitches don't hold or the garment does not come out as one would hope that the political conviction of the students begins to falter. It is not for a lack of care or understanding that shopping at H\&M is harmful to ones' health, to other people and the planet in general that my students find it hard to transform their habits; but it is down to the laborious aspects of learning new skills and enduring the feeling of being not good at doing something. It is when learning how to mend clothes feels hard that my role becomes particularly important in relation to the political project we all already share. (Conforti 2015)

As with other reproductive labours, the work of both repair and pedagogy are often the unacknowledged ones. The skillful aspects of making and repair often sit on a long learning curve 
where sustaining yourself and others through failure and falters is no small feat. The ongoing, continuous repair in taking care of these practices and groups is reflected on, regretfully, by Hacker and activist Mel Chua:

The environments where I was trying to "learn about nerdy stuff" were sociotechnically broken in a way that made it hard for me (as a disabled minority woman, among other things) to join in. If I wanted to even start being part of the technical community, I had to start by fixing the technical community — patching the roof and fixing the plumbing, so to speak — before I could even walk inside and start to live there. [...] I told myself, at least I was in the building. And I saw that my "janitorial" work made it possible for other people to enter the building and do the things they wanted to do - which were often the things I wanted to do, too! — and so I thought: okay. That's okay. At least somebody gets to do it. I can see my gift to the community doing so much good, that I will give up my desire to learn and do the technical things! (Chua 2015)

Chua writes of a variety of different labours needed and amongst the 'janitorial work' she writes about she also includes the emotional labour she invested with individuals as well as, the hosting and coordinating of many meetings. This slow and time consuming work was without immediate reward and, as Chua writes, took her away from her own desires. The point here, is that for repair practices to be empowering processes they will also have to take care of the socio-political environment and context in which they take place. It is not just learning technical skills and knowledges but the spaces themselves need to be 'socio-technically' fixed to become transversal and intersectional socialization spaces.

\section{Sociality of Collective Repair}

The final aspect is that collective repair practices are highlighting their role as platforms for sociality within their locales. By sociality we mean the experience of the presence of others as a 
source of reciprocal pleasure, in other words, a subcategory of the much vaster realm of 'the social' as examined by the social sciences. Fixers initiatives often take up the form of festivals to highlight the convivial aspect of their operation, appearing as wanting to 'repair' the social fabric of their local communities.

Many other organizers and commentators alike have remarked that those who participate in collective making and repairing do so not only through their shared interests in technology or crafts, but importantly because of a desire for social encounters (Sleigh, Stewart and Stokes 2015). One commentator from the Sussex Energy Group at SPRU reported on his own encounter with the world of repair cafes:

More fascinating for me, however, were glimpses of a more social rather than technical aspect to repair. Some grassroots innovators at the conference were incredibly aware of the affective issues in repair, and which they used to inform their activities. So the idea with Repair Café is not simply to access a volunteer expert who can fix your stuff, but to be encouraged and helped into having a go yourself, and developing your own skills and knowledge; and then sticking around to help other people, perhaps drawing out capabilities in yourself that you were not so aware you had. There is an emphasis on sociability, skilling, sharing, and being part of something. These initiatives are not solely about a repair service provision where it was previously absent. Emphasis in many of these initiatives rests in the social relationships in repairing stuff. (Smith 2014)

Or in the words of some of the restarter volunteers, interviewed by David Pickering:

The name is a clue really. It's a 'party', you go along, you meet people you've never met before, you engage with them, it's a nice fun atmosphere, the people who'll turn up as restarters like myself are genuinely into fixing things so they enjoy it as well (Restart Project 2015b) 
It's a party very much so because we want people to have fun, to have a good time and have a social opportunity to interact with others, and it's a restart party because people come with the hope they can learn something about a device that is broken or malfunctioning by being paired with a volunteer that is more experienced in taking apart, troubleshooting and repairing that kind of device. (Restart Project 2015b)

In accounts such as these, the link between learning and conviviality is often emphasised as key to the greater political ethos of the initiatives in terms of sustainability and empowerment in the face of technologies. As with the dimensions of property and pedagogy, here too it seems the variety and vitality of praxis within repair movements accommodates a wide spectrum of interpretations of the political currency of sociality. As Ursula Huws has argued, the ubiquitous 'colonization of ... sociality by the market has not only generated a new source of profit-making but has also helped to drive wedges into the fabric of ... social lives, undermining the basis for future solidarities' (Huws 2015). Under which conditions could repair practices constitute one of such basis for future solidarities? If the sociability afforded in collective repair is to become a fully political rather than only a recreational phenomenon, then it is important to discuss what kind of sociality is at stake, rather than simply putting 'being social' forward as a value in itself, confining the political to the realm of collectivism. The point of strengthening community ties is a value insofar as it can contribute to bring about a greater social justice, more democratic and accountable power dynamics, more protection against abuses of all kinds, and more mutuality that strengthens one's autonomy from dominant institutions such as the market and the state. Sociality however risks becoming less progressive, if it does not reflexively consider how that social body is composed and relates. For example, a sociality that is based on spontaneous similarities, real or imagined, within members risks producing a selected community based unwittingly on some a priori principles of exclusion. This is a vast problematic, one that has been extensively reflected upon by philosophers and social scientists alike, and it is beyond our scope to confront it here. We will however draw out some of the specificities that repair practices bring to the question of sociality, and their implications for the kinds of knowledges and processes of individuation they are able to produce. Our hypothesis is that the 
sociality of collective repairs can become a significant moment of politicization when it becomes not only an occasion of environmental commitment, but when it is also understood as a potential locus of anti-work tactics.

Anti-work politics is a longstanding trope in social and political theory (Weeks, 2011). In recent years, it has gained some new traction following the international popularity of Italian Autonomous thought (cf. Hardt and Virno 2006, Lotringer and Marazzi 2007), which postulated that the capacity for innovation comes from the resistance of people to the regime of work, rather than from an intrinsic innovative capacity of capital. In this analysis, the knowledges and abilities of subjects to dwell in their environments is systematically subtracted from them by the technologies and machines created by capitalism, which are then sold back to them in the form of a product later on. The antiwork argument is that in being put to work humans actually become deskilled as a result. Consequently, a constellation of anti- and post- work theorists ${ }^{4}$ encourage us to reject the work ethics that informed the industrial phase of development, not least because the incessant growth of capitalism has now dangerously approached the absolute limit of ecological collapse. As it becomes more urgent to move away from an economy based on ever-increasing production, extractivism, and growth, repair practices will acquire a more important role in redefining what kind of forms of life we could collectively create, in a world where full automation has the potential to make increasing numbers of jobs redundant. The ongoing expansion of smart objects and the introduction of automation replacing human labour has been described in terms of a postwork society (Aronowitz and Cutler 1998), and yet many have remarked how this technological shift is not at all resulting in less, but more work (paid or unpaid) for all. As Ursula Huws (2015) has put it

domestic labor was increasingly transformed into what I termed 'consumption work,' sucking ever more activities out of the private sphere of direct interpersonal interaction and bringing them into a public marketplace. The more workers become dependent on these new commodities to survive from one day to the next, the greater their need for a source of income to pay for them, tightening capitalism's grasp on their lives still further.

\footnotetext{
${ }^{4}$ Such as Stanley Aronowitz and Jonathan Cutler, Bob Black, David Freyne, Andre Gorz, Helen Hester, John Hughes, The Krisis Group, Paul Mason, Kati Weeks, among many others.
} 
As Elizabeth Spelman noted, across many different cultures the household traditionally constitutes a privileged site of fixing and mending (2002, p. 26). Yet since the second half of the 20th century, the household as site of domesticity and 'private' relations has been subject to deep transformations brought on by both critiques of the nuclear family and growing subsumption by the market. The home, while still a site of social reproduction, is increasingly integrated into the market with all the 'consumption work' required to make it function. As Illich (1972) noted market expansion is accompanied by processes of deskilling, to which repair has also been subject. Feminist scholars have noted that such deskilling is characterised by a gendered dimension, amongst other hierarchies. Analysing changes in industrial production and office work environments in Europe and the USA, feminists argued that advances in our technologies involve both a simultaneously upskilling and downskilling, where those tasks 'down-skilled' by new technologies were feminised and the upskilled, new technologically 'advanced' skills seen as correlating with masculine identities and tasks (Wajchman 1991).

In reaction to this, the spread of a repair ethic could be seen as contributing to an antiworkerist stance that refuses the 'productivist bias' (Jackson 2014, p. 234) of life put to work. Repair movements offer a performative critique of a capitalist society based on work as the 'primary force of social mediation' (Postone 1996, p. 49). Repair as an activity and form of labour can therefore be located in the feminist political context of reproductive labour. Collective repair constitutes an interesting form of reproductive labour that goes beyond the family and the household. These movements are contributing to the shift from repair seen as a 'family responsibility to societal imperative' (Rosner and Ames 2014, p.55), thus reframing the conversation around life and work. As Kathi Weeks writes:

What if the older division between reproduction and production were to be replaced with the distinction between life and work? [...] There are, it seems to me, certain potential benefits of such a framework. For one thing, compared to the category of reproduction, life has the advantage of being a more capacious concept. As a more 
expansive category it does not risk corralling the practices constitutive of social life into the space of the household or, even more narrowly, equate them with the institution of the family. Thus the political struggle that poses life against work is less readily equated with and reduced to the project of re-valuing the private world of the family and defending its traditional values. (2007, p. 246)

In supporting anti-work politics repair provides some routes away from consumptive labour, as well as a way to freely access convivial occasions. This latter point is particularly pressing at a time when consumption is becoming the only way to access such occasions and the resources for it (such as going to the cinema, drinking out, shopping). Collective repair practices are putting forward a different mode of valorizing reproductive and maintenance labour away from the household, as they make it into a sociable practice. They are doing so at a threshold moment, as what started as a process of deskilling- forgetting how to fix and mend, less opportunities and time to practice and transmit such practical knowledge - is currently not only intensifying, but also turning into a veritable strategy of blockage against the social use and transmission of repair skills. These informally learned skills of repair were part of a broader ecology of subsistence activities that provided a pool of resources, knowledges and interdependent relations of practical solidarity, which until recently have been a vital component of oppressed communities and key to the formation of working class subjectivities. In this respect, the elimination of repair skills can be also read politically as an attack on the mesh of relations that constitute a practical kernel of anti-work ethics, as a way to resist the ever increasing reliance upon formal wage relations and capitalist commodities (and the work ideology that comes with it).

Collective repair can thus be seen as a site for re-skilling subjects who have been stripped of the opportunity to learn how to intervene in the materiality of everyday lives. In so doing, it counters the action of management discourse that is relentlessly intent on figuring out more tactics to dispossess workers of their knowledges to embed them into automated systems that are privately owned (Sholz 2015). Conversely, the sociality of repairing risks to become a form of acquiescence with the present neoliberal discourse that promotes self-reliance and resilience as a form of self-sufficiency that embraces the ongoing impoverishment of society. 
Two polar examples, interesting for their close geographic and temporal proximity, illustrate this last point: the workers of Ri-Maflow, an occupied factory in Trezzano sul Naviglio, Italy, and Milano non si tocca! [Hands off Milan! in English] a conservative 'grassroots' initiative to tidy the city. RiMaflow is one of the factories that was shut down after the financial crisis and subsequently occupied by its formers workers who transformed it into a cooperative productive unit. What is relevant for our present topic is that Ri-Maflow occupiers highlighted the new social ethos of their reclaimed plant by reconverting the production from spare automobile parts to fixing and reselling used household appliances such as fridges, washing machines and pcs (Ri-Maflow n.d.). In this case, repair was seen as an activity that would generate new skills among the occupying workers and invent a sustainable new 'product' line, in accordance with their ethos of solidarity. In contrast, Milano non si tocca! were squads of volunteers who took the streets to clean up and 'fix' the damages provoked during the Mayday protests - protests that were directed against the numerous scandals associated with the Expo 2015 held in the same city (Bascetta and Mezzadra 2015). Here, the rhetoric of repairing a damage done is linked to a restorative ethos that excludes the possibility of social dissent. In this latter social initiative, the 'humbleness of repair' has been substituted with the very different attitude, that of an 'arrogance of correction' (Spelman 2002). Repair's compatibility with neoliberal discourses around self-reliance and voluntary performance is particularly visible when the collective efforts of fixing avoid confronting broader systemic forces. If a political demand for a systemic change in the cycle of production is not included in a reparative intervention, the danger is to turn their sociality into a well meaning yet harmful retreat from the real varsity of the problem at hand.

As with property and pedagogy, the sociality of collective repair also addresses the contradictions of the present moment, as it prefigures the coming postwork society, between the possibility of creating a more diffused anti-work culture based on social care and the risk of acquiescing with an all pervasive ethic of work.

\section{Conclusion}


In this paper, we have outlined the emergence of what we suggest can be seen as a 'repair lifestyle movement' across the affluent, urban societies of the 'global North'. We have described some of the ways such collective repair practices surface important political tensions in everyday life and as such poses opportunities for its transformation. Bringing us into direct contact with expanding proprietary systems and enclosures, repair practices are actively challenging those systems by encouraging transgressions, in realms that span from IP to independent licences to fix material goods. By tracing the resonances between the concerns put forward by campaigns such as the Repair Assiciation and discourses and movements for the common, the ethos of repair and taking care of objects has, we suggest, the potential to bring us into different kinds of (social) relations with objects, as well as alter notions of property, rather than contributing to its recentering as a consumer right. Repair thus might be one way in which we learn to become 'useful' again to the things we own (custodians.online 2015), rather than the other way around.

Moreover, collective repair practices are pedagogical sites that also bring many other relations that need to be 'fixed' to the fore, particularly around gender and the construction of expertise as constitutive elements of subjectivity. By examining the gap between the aspiration of initiatives such as the Restarter Parties and the difficulties experienced by participants and teachers alike in confronting complex repair, we considered the difficulties in sustaining inclusive learning. Drawing on feminist scholarship, we considered how on the one hand these collective sites of repair run the risk of reinforcing existing gender and knowledge hierarchies, but on the other hand they also present an opportunity for the exposure and reconfiguration of what needs to be 'fixed' in pedagogy.

Finally, by examining the status of repair as a practice situated at the intersection of alternative consumption and alternative production, we reflected on how the 'right to repair' expresses both a frontline in the struggle to the right to access to independent livelihood, but at the same time they put forward an aspiration of sociality (often expressed by those involved as 'community') that prefigures a de-centering of work altogether. In other words, collective repair practices, are bringing into the public realm this otherwise unacknowledged form of reproductive labour (Federici 2004, Dalla Costa and James 1972), potentially provoking significant shifts in perspective away from 'innovation,' to emphasise the learning and invention that occurs through the taking-care of things (Jackson 2014, Graham and Thrift 2007, Russell and Vinsel 2016). 
To conclude, collective repair is not only part of creating a different material relation with objects, but it has to work with cultural values and lifestyles. It takes issues with the dominant desire for the new that is presented as a quality of commodities rather than as an expression of evolving social relations. This is why the appearance of a collective repair movement is significant, because it is has the potential to make the effort for this redefinition of time not about private lifestyle choices reserved to the urban creative classes. Instead of mythicizing individual efforts, often destined to remain mediocre or short lived attempts at repair, whose results would never be as good as a newly made, industrially produced and design items, they have the chance of intervening more significantly in the collective political imaginary by positing this challenge as a common one. In so doing, the movement would have a chance to develop beyond its present clustering in specific urban milieus of the Global North, allowing it to establishing transnational solidarities and organising opportunities together with the Global South, which is actually in many ways at the forefront of developing material cultures and vernacular infrastructures around maintenance, recycling and repurposing. If this is to happen is still uncertain however, and further research will be called for. Whichever way this will unfold, as argued in this article, we believe that questioning private property, received pedagogical models and the prevalent productivist ethic will remain crucial to its force.

\section{References}

Aronowitz, S., and Jonathan C., 1998. Post-work: The wages of cybernation. London and New York: Routledge.

Bascetta, M., and Mezzadra, S., 2015. La prova di forza che mima la rivolta che non c'è. Il Manifesto, 5 May.

Boggs, C., 1977. Marxism, prefigurative communism and the problem of workers' control. Radical America, 6 (Winter), 99-122.

Bluff, J., 2015. Repairman takes Keurig to task over unfixable machines [online]. iFixit Blog Post 21 December 2015. Available from : https://ifixit.org/blog/7668/unfixable-keurig/ [Accessed 20 February 2016].

2016. Recyclers assert their right to repair [online]. iFixit Blog Post 03 February 2016. Available from: http://ifixit.org/blog/7876/recyclers-right-to-reuse/ [Accessed 24 February 2016].

Brand, S. 1994. How buildings learn. What happens after they're built. New York: Viking.

Brignall, M., 2016. 'Error 53' fury mounts as Apple software update threatens to kill your iPhone 6, The Guardian Friday 5 February 2016. Available from:

http://www.theguardian.com/money/2016/feb/05/error-53-apple-iphone-software-updatehandset-worthless-third-party-repair [Accessed 20 February2016]. 
Carolan, M. S., 2010. The mutability of biotechnology patents. From unwieldy products of nature to independent 'object/s'. Theory, Culture and Society 27 (1), 110-129.

Chamberlain, E., 2012. How Nikon is killing camera repair [online]. iFixit blog post 14 February 2012. Available: http://ifixit.org/blog/1349/how-nikon-is-killing-camera-repair/ [Accessed 21 February 2016].

Chau, M., 2015, On the diversity-readiness of STEM environments: 'It's almost as if I could only enter the makerspace as a janitor.' Available from: http://blog.melchua.com/2015/04/28/on-thediversity-readiness-of-stem-environments-its-almost-as-if-i-could-only-enter-themakerspace-as-a-janitor/ [Accessed 03 March 2016].

Conforti, S., 2015. Interview with author, August.

Cooper, T. et al., eds., 2015. Product lifetimes and the environment conference proceedings. 17-19 June 2015, Nottingham.

Crary, J., 2013. 24/7: Late capitalism and the ends of sleep. London and New York: Verso Books.

Custodians.online, 2015. In solidarity with Library Genesis and Sci-Hub. Available from: http://custodians.online/ [Accessed 02 March 2016].

Dardot, P. and Laval, C., 2015. Del comune o della rivoluzione nel XXI secolo. Rome: Deriveapprodi.

Dalla Costa, M., and James, S., 1972. The power of women and the subversion of the community. Bristol: Falling Wall Press.

De Angelis, M., 2007. The beginning of history. Value struggles and global capital. London: Pluto Press.

Denis, J., Mongili, A., and Pontille, D., eds., 2015. Maintenance and repair, special issue of Tecnoscienza, Italian Journal of Science \& Technology Studies, 6 (2), December.

Diani, M., 1992. The concept of social movement. The Sociological Review, 40 (1), 1-25.

Ellsworth, E., 1989. Why doesn't this feel empowering? Working through the repressive myths of critical pedagogy. Harvard educational review 59 (3), 297-325.

Federici, S., 2004. Caliban and the witch: Women, the body and primitive accumulation. New York: Autonomedia.

Foucault, M., 1980. Power/knowledge: Selected interviews and other writings, 1972-1977. New York: Pantheon Books.

Fulton Suri, J., 2009. Care and repair. Strengthening the bonds with the things we buy. Patterns 30 [online], Available from:

http://patterns.ideo.com/images/uploads/pdf/patterns_vol3_care_repair_final.pdf [Accessed 30 August 2016].

Gorz, A., 1968. The way forward. New Left Review, 1, 47-66.

Graham, S. and Thrift, N., 2007. Out of order: Understanding maintenance and repair. Theory, Culture and Society 24(3), 1-25.

Haenfler, R., Johnson, B. and Jones, E., 2012. Lifestyle movements: Exploring the intersection of lifestyle and social movements. Social Movement Studies, 11 (1), 1-20.

Hardt, M., and Paolo V., 2006. Radical thought in Italy: A potential politics. University of Minnesota Press.

Hardt, M., and Antonio N., 2009. Commonwealth. Cambridge, MA: Belknap Press of Harvard University Press.

hooks, b., 1994. Teaching to transgress: Education as the practice of freedom. New York: Routledge. Huws, U., 2015. iCapitalism and the cybertariat. Contradictions of the digital economy. The Monthly Review, 66 (8) [online]. Available from: http://monthlyreview.org/2015/01/01/icapitalismand-the-cybertariat/ [Accessed 15 January 2016].

iFixit, nd.a. About iFixit. Available from: https://www.ifixit.com/info [Accessed 28 February2016]. 
iFixit, nd.b. Supports the Community. Available from: https://www.ifixit.com/Info/Activism [Accessed 28 February 2016].

iFixit, nd.c. Right to Repair. Available from: http://ifixit.org/right [Accessed 28 February 2016].

iFixit, nd.d. Self-Repair Manifesto. Available from: https://www.ifixit.com/Manifesto [Accessed 28 February 2016].

Gelber, S.M., 1997. Do-it-yourself: constructing, repairing and maintaining domestic masculinity. American Quarterly, 49 (1), 66-112.

Jackson, S. J., 2014. Rethinking repair. In: Gillespie, T., Boczkowski, P., and Foot, K., eds., Media technologies: Essays on communication, materiality and society. Cambridge, MA: MIT Press

Jager, S. and Maier, F. 2009. 'Theoretical and methodological aspects of Foucauldian critical discourse analysis and dispositive analysis'. In Wodak, R. and Meyer, M. eds., 2009. Methods for critical discourse analysis. Sage. pp. 34-61.

Littler, J., 2009. Radical consumption: Shopping for change in contemporary culture. Berkshire: Open University Press.

Lotringer, S., and Marazzi, C., 2007. Autonomia: Post-political politics. Vol. 1. Semiotext(e).

Meiners, E. and Quinn, T., 2007. How real does it get? Editorializing on critical pedagogy, wankstas and the fear of teaching like a girl. How We Learn, 11 October. Available from: http://areachicago.org/how-real-does-it-get/ [Accessed 2 February 2016].

Murthy, D., 2011. 'Emergent digital ethnographic methods for social research,' In Sharlene HesseBiber, ed. The Handbook of Emergent Technologies in Social Research. New York: Oxford University Press, pp. 158-179.

Nelson, G., 2014, Automakers agree to 'right to repair' deal. Automotive News, 25 January. Available from: http://www.autonews.com/article/20140125/RETAIL05/301279936/automakers-agreeto-right-to-repair-deal [Accessed: 05 March 2016].

Ostrom, E., 1990 Governing the commons: The evolution of institutions for collective action. The political economy of institutions and decisions. Cambridge University Press.

Packard, V., 1960. The Waste Makers. London: Longmans Green and Co.

Postone, M., 1996. Time, labor, and social domination: A reinterpretation of Marx's critical theory. Cambridge University Press.

Ratto, M. and Boler, M., 2014. DIY citizenship: Critical making and social media. Cambridge, MA and London, UK: MIT Press.

The Repair Association, nd.a. About the Association. https://repair.org/association/ [Accessed 28 February 2016].

The Repair Association, nd.b. https://repair.org [Accessed 28 February 2016].

The Repair Cafe, nd. About the Repair Cafe. http://repaircafe.org/en/about/ [Accessed 15 February 2016].

Restart Project, nd. 'Information about the Restart Parties. In: Restart Project media kit. Available from: https://therestartproject.org [Accessed 10 February 2016].

Restart Project, 2015a. Where are the women fixers? Restart Radio, 21 October. Available from: https://therestartproject.org/podcast/restart-radio-where-are-the-women-fixers/ [Accessed: 25 February 2016].

Restart Project, 2015b. Introducing the Restart Podcast. Available from: https://therestartproject.org/podcast/introducing-the-restart-podcast/ 8th April 2015 [Accessed 03 March 2016].

Restart Project, 2016. Makers and fixers, 'Error 53' iPhone scandal. Restart Radio, 10 February. Available from: https://therestartproject.org/podcast/makers-and-fixers/ [Accessed: 17 February 2016].

Ri-Maflow. www.rimaflow.it [Accessed 03 March 2016].

Robb, J., 2012. Punk rock: an oral history. Great Britain: PM Press. 
Rosner, D.. K., and Ames, M. G., 2014. Designing for repair? Infrastructures and materialities of breakdown. CSCW'14. Available from: http://www.danielarosner.com [Accessed 17 February 2016].

R-Riparabile, 2015. r-riparabile.com [Accessed 04 August 2016].

Russell, A. and Vinsel, L., 2016. Hail the Maintainers. Aeon, 7 April. Available from: https://aeon.co/essays/innovation-is-overvalued-maintenance-often-matters-more [Accessed 02 May 2016].

Sholz, T., 2015. Think Outside the Boss [online]. Available from: http://www.publicseminar.org/2015/04/think-outside-the-boss/\#.Vugjt8paJaV [Accessed 29 January 2016].

Siemens, 2014. Facts and Forecasts: Billions of Things, Trillions of Dollars [online]. Available from: http://www.siemens.com/innovation/en/home/pictures-of-the-future/digitalization-andsoftware/internet-of-things-facts-and-forecasts.html [Accessed 24 February 2016].

Sleigh, A., Stewart, A., and Stokes, K., 2015. Open Dataset of UK Makerspaces. A User's Guide. Report for Nesta, London. Available from: http://www.nesta.org.uk/publications/opendataset-uk-makerspaces-users-guide [Accessed 22 May 2016].

Smith, A., 2014. Makers, fixers and circular economies. Sussex Energy Group at SPRU blog, 25 June. Available at: http://blogs.sussex.ac.uk/sussexenergygroup/2014/06/25/makersfixers-and-circular-economies/ [Accessed 31 January 2016].

Snow, D. A., 2004. Social movements as challenges to authority: Resistance to an emerging conceptual hegemony. Research in social movements, conflicts and change 25 (1), 3-25.

Spelman, E.V., 2002. Repair: The impulse to restore in a fragile world. Boston: Beacon Press.

Spring, J. H., and Illich, I. D., 1972. Education and the rise of the corporate state. Boston: Beacon Press.

Vercellone, C., 2010. The crisis of the law of value and the becoming-rent of profit. In: Fumagalli, A. and Mazzadra, S., eds., 2010. Crisis in the global economy: Financial markets, social struggles and the new political scenarios. Los Angeles: Semiotext(e).

Verdeja, E., 2008. A critical theory of reparative justice. Constellations 15 (2), 208-222.

Wajchman, J. 1991. Feminism confronts technology. Cambridge: Blackwell.

Weeks, K., 2011. The problem with work: Feminism, Marxism, antiwork politics, and postwork imaginaries. Duke University Press.

2007. Life within and against work: Affective labor, feminist critique and post-fordist politics.

Ephemera. Theory and politics in organization, 7(1), 233-249.

Weins, K., 2011. Apple's Diabolical Plan to Screw Your iPhone [online]. Available from: http://www.ifixit.com/blog/2011/01/20/apples-diabolical-plan-to-screw-your-iphone/ [Accessed 18 February 2016].

Wrap, 2016. Sustainable Textiles [online]. Available from: http://www.wrap.org.uk/sustainable-textiles [Accessed 12.07.2016]. 